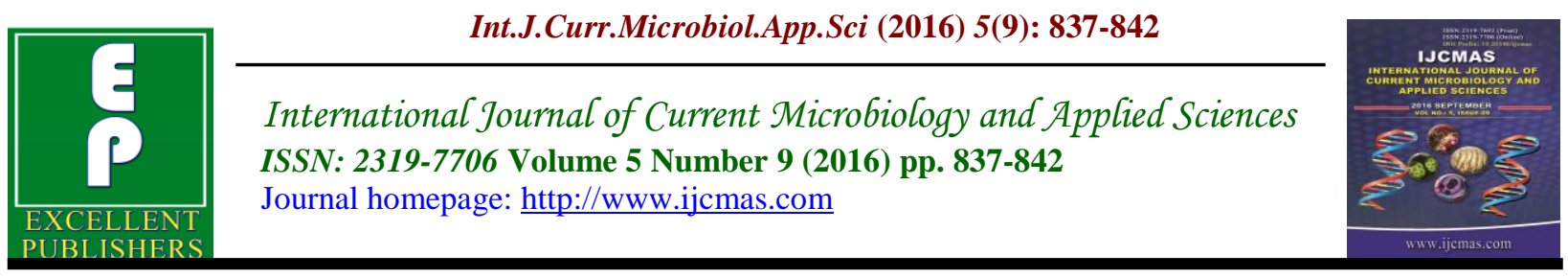

Original Research Article

http://dx.doi.org/10.20546/ijcmas.2016.509.094

\title{
Genetic Diversity and Relationship of Selected Cultivars of Rice, Oryza sativa L. using Random Amplified Polymorphic DNA (RAPD) Markers
}

\author{
B.R. Roopa and B.K. Chikkaswamy* \\ Department of Biotechnology, Sigma Bioscience Research Center, \# 530, \\ 16th Cross, 2nd Stage, Indira Nagar, Bangaluru-560038, India \\ *Corresponding author
}

\begin{tabular}{|c|c|}
\hline & A B S T R A C T \\
\hline & \multirow{4}{*}{$\begin{array}{l}\text { The genetic diversity in } 26 \text { selected cultivars of rice, Oryza sativa L. using } \\
20 \text { decamer random primers. Out of } 20,15 \text { RAPD primers revealed } \\
\text { polymorphism while the remaining } 5 \text { primers showed no reaction. The } \\
\text { primers produced a total of } 71 \text { bands of which } 66 \text { were polymorphic } \\
(95.2 \%) \text {. The number of polymorphic fragments for each primer varied from } \\
1 \text { to } 3 \text { with an average of } 2.53 \text { polymorphic fragments. The primer OPA-19 } \\
\text { produced the maximum number of polymorphic bands. The RAPD data was } \\
\text { analyzed to determine the genetic similarity coefficients which ranged from } \\
0.46 \text { to } 0.81 \text {. Cluster analysis was performed using Ward's method) using } \\
\text { the Jaccard's similarity coefficient. The Wards method dendrogram resolved } \\
\text { the selected rice cultivars into two to three major clusters. }\end{array}$} \\
\hline $\begin{array}{l}\text { Genetic variation } \\
\text { molecular } \\
\text { markers } \\
\text { Oryza sativa } \\
\text { Ward's } \\
\text { method. }\end{array}$ & \\
\hline Article Info & \\
\hline $\begin{array}{l}\text { Accepted: } \\
\text { 28 July } 2016 \\
\text { Available Online: } \\
10 \text { August } 2016\end{array}$ & \\
\hline
\end{tabular}

\section{Introduction}

The genus Oryza contains 25 recognized species, of which 23 are wild species and the remaining two are $O$. sativa and $O$. glaberrima which are cultivated species (Brar and Khush, 2003; Chang, 2003). O. sativa is the most widely grown worldwide including in Asian, North and South American, European Union, Middle Eastern and African countries. The world's rice production has doubled during last 25 years, largely due to the use of improved technology such as high yielding varieties and better crop management practices
(Byerlee, 1996). Demand for rice is growing every year and it is estimated that in 2025 $\mathrm{AD}$ the requirement would be 140 million tones. The land available for cultivation is decreasing due to continuous urbanization and inappropriate Rice (Oryza sativa L.) is one of the most important crops that provide food for more than half of the world population (Malik et al., 2008). India has a long history of rice cultivation and stands first in rice area and second in rice production, after China. Approximately 90\% of the world's rice is grown in the Asian 
continent and constitutes a staple food for 2.7 billion people worldwide (Salim et al., 2003; Paranthaman et al., 2009).

Further scope of crop improvement depends on the conserved use of genetic variability and diversity in plant breeding programmes and use of new biotechnological tools. Molecular characterization can reveal the maximum genetic variation or genetic relatedness found in a population ( $\mathrm{Xu}$ et al., 2000). Chakravarthi and Naravaneni (2006) reported the usefulness of preservation and conservation of genetic resources since genetic diversity provides information to monitor germplasm and prediction of potential genetic gains. Information regarding genetic variability at molecular level could be used to help, identify and develop genetically unique germplasm that compliments existing cultivars (Ni et al., 2002; Ravi et al., 2003; Chakravarthi and Naravaneni, 2006). land use (Khush, 1997; Fischer et al., 2000). To sustain present food self sufficiency and to meet future food requirements, India has to increase its rice productivity by 3 per cent per annum (Thiyagarajan and Selvaraju, 2001). DNA based molecular markers have proven to be powerful tools in the assessment of genetic variation and in the elucidation of genetic relationships within and among the species of rice (Ragunathanchari et al., 1999, 2000; Shivapriya and Hittalmani, 2006). The present investigation was undertaken for the assessment of genetic diversity among the selected rice cultivars with the help of RAPD markers.

\section{Materials and Methods}

Plant materials and genomic DNA isolation The plant materials selected for the present study were 26 different cultivars of rice. The seeds of 26 varieties such as Sakha 101, Sakha 102, Giza 172, Giza 178, Amber,
Furat, Yasmin, Mashkhab, Mashkhab, Branage-4, Al-abasia, Daawat, Aamchur, DPT-52, Gonor-1, Gundra, Guntur-2, Jeera Shankar, Komal, MTU, Patel-3, Shavagi, SHPP-20, Sonam, Soma, SS20, were collected from Rice Research Station, GKVK AND from farmer field of Karnataka , India. From traditional farmers of Karnataka , India. Healthy seeds of each variety were sowed in soil pots containing water under appropriate growth conditions for getting fresh leaves. DNA extraction was carried out from the fresh leaves collected from tillers following cetyl trimethyl ammonium bromide (CTAB) method (Doyle and Doyle, 1987) with some modifications. Freshly germinated 500 milligrams of young leaves were ground to a very fine powder in liquid nitrogen and dispersed in $3 \mathrm{~mL}$ of prewarmed $(65 \mathrm{o} C)$ CTAB DNA extraction buffer (2\% CTAB; $1.4 \mathrm{M} \mathrm{NaCl} ; 100 \mathrm{mM}$ Tris-HCI, pH 8.0; 20 mM EDTA, p.H. 8.0; $0.2 \%$ - mercaptoethanol (added just before use). Oakridge tubes containing samples were incubated at $650 \mathrm{C}$ for $30 \mathrm{~min}$ in a water bath. The samples were swirled every $10 \mathrm{~min}$. After incubation the mixture was cooled down to room temperature and emulsified with an equal volume of chloroform: isoamyl alcohol (24:1) and centrifuged at $8000 \mathrm{rpm}$ for $10 \mathrm{~min}$. Following centrifugation, the aqueous phase was collected and nucleic acid was precipitated by mixing with equal volume of chilled isopropanol. The precipitated nucleic acid was centrifuged at $12000 \mathrm{rpm}$ for 10 min and the pellet was washed with $70 \%$ ethanol. The DNA pellet obtained was dried and stored in $400 \mu \mathrm{L}$ TE buffer.

\section{Purification of DNA}

The RNA was removed by RNase treatment at $37 \mathrm{o} \mathrm{C}$ for $30 \mathrm{~min}$ in a water bath. After incubation, DNA solution was extracted with an equal volume of chloroform: 
isoamyl alcohol (24:1). The upper aqueous phase was collected after centrifugation at $8000 \mathrm{rpm}$ for $10 \mathrm{~min}$ and mixed with $50 \mu \mathrm{L}$ of $3 \mathrm{M}$ sodium acetate. DNA was precipitated by adding two volumes of chilled absolute alcohol. The DNA pellet was air dried and dissolved in $100 \mu \mathrm{L}$ TE buffer. Two $\mu \mathrm{L}$ of genomic DNA isolated was subjected to electrophoresis on $0.8 \%$ agarose gel containing $1 \mathrm{mg} / \mathrm{mL}$ ethidium bromide and the quantity of genomic DNA was assessed using undigested lambda DNA as control. For further use in PCR the DNA was diluted to a concentration of approximately $25 \mathrm{ng} / \mu \mathrm{L}$.

\section{RAPD analysis}

For the RAPD analysis of rice cultivars thirty deca-nucleotide primers of Operon Technology Inc. (Alameda, CA, USA) were used. The reaction was carried out in $25 \mu \mathrm{L}$ reaction volume containing 25 nanogram genomic DNA, $2.5 \mu \mathrm{L}$ 10X PCR buffer, 2 $\mu \mathrm{L} 25 \mathrm{mM} \mathrm{MgCl} 2,2.5 \mu \mathrm{L} 2.5 \mathrm{mM}$ dNTPs, $0.4 \mu \mathrm{L}$ Taq DNA polymerase and $2 \mu \mathrm{L}$ primer. All the reaction chemicals except primers were procured from $\mathrm{M} / \mathrm{s}$. Genei, Bangalore, India

\section{RAPD amplification procedure}

Samples for amplification were carried out using the method stipulated by Williams et al. (1990) with some modifications of thermal cycles. Amplification was performed in a thermal cycler with an initial denaturation of $94 \mathrm{o} \mathrm{C}$ for $5 \mathrm{~min}$ followed by 35 cycles which contains denaturation at 940 $\mathrm{C}$ for $1 \mathrm{~min}$ followed by annealing in which the annealing temperature was adjusted based on the Tm value of each primers and finally extension at 72o $\mathrm{C}$ for $2 \mathrm{~min}$. After 35 cycles, there was a final extension step at $72 \mathrm{o} \mathrm{C}$ for $10 \mathrm{~min}$. All the reactions were amplified in a Gradient Palmcycler (Corbett Research, CG-96, Australia). Each amplification reaction for the screened primers was replicated two times individually with the same procedure in order to verify that the RAPD markers were reproducible and consistent.

\section{Electrophoresis and visualization of RAPD products}

Amplified products were fractionated by $1.5 \%$ agarose gel in $1 \mathrm{X}$ TBE buffer (pH-8.0) at $100 \mathrm{~V}$ for $2 \mathrm{~h}$ and stained with ethidium bromide. $1 \mathrm{~kb}$ DNA ladder was used as size marker. The gels were visualized under a UV transilluminator and documented using a digital camera. Total number of bands and number of polymorphic bands present in each cultivar was detected from the gels and scored manually. Each polymorphic band was considered as binary characters and was scored 1 (presence) or 0 (absence) for each sample. Only those fragments with medium and high intensity were taken into consideration.

\section{Data analysis}

The gel images were scored using a binary scoring system that recorded the presence and absence of bands as " 1 " and " 0 " respectively. From the binary data, the similarity coefficient values between the cultivars were derived based on the probability that a particular character of one accession will also be present in another with the Jaccard's correlation analysis using the statistical software. The statistical analysis is performed using Euclidean distance method statica 5.0 in order to cluster the accessions.

\section{Results and Discussion}

The results of present study indicated a considerable level of genetic diversity among the cultivars selected. Among 20 primers used in this study, results of 15 
primers were taken into consideration since they had given reproducible bands. Each polymorphic RAPD marker was considered as a locus so that every locus had two alleles, identified by the presence and absence of the band. A total of 428 DNA fragments were generated by 15 primers out of which 66 were polymorphic (95\% polymorphism) (Table 2). Out of 20 primers, only 15 primers exhibited more than $90 \%$ polymorphism. The number of polymorphic fragments for each primer varied from 65-71 with an average of 2.73 polymorphic fragments. The primer OPA-17 produced the maximum number of polymorphic bands. The percentage of polymorphism was calculated as $95 \%$. The size of amplified fragments ranges between $300 \mathrm{bp}$ to $3000 \mathrm{bp}$ (Figure 1). It was observed that the level of polymorphism with primers differed between the cultivars. Similarity between the cultivars was derived by Jaccard's correlation coefficient (Jaccard, 1908). Correlation matrices obtained from all the primers used were consolidated in one single matrix and the mean values were presented (Table 3). Jaccard's pair-wise similarities computed between the cultivars showed that Sakha 101, Sakha 102, were the closest $(0.91)$. The greatest distance was observed between the cultivars Daawat, and SS20, (0.46). RAPD data generated by twenty primers were subjected to Wards Euclidean distance cluster analysis and the dendrogram was constructed (Figure 2). Cluster analysis revealed the similarity between the rice cultivars and it ranged from $50 \%$ to $80 \%$. The dendrogram classified the cultivars into two distinct clusters. The first cluster included three cultivars, Shavagi, SHPP-20, Sonam, . The second cluster included 21 cultivars collected from Farmers field of Tumkur .

Fig.1 RAPD molecular markers in Rice varieties amplified by OPA-19

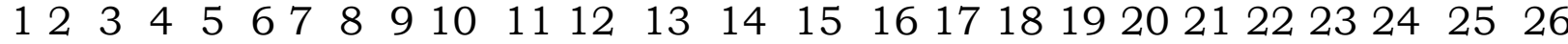

The present investigation revealed the effectiveness of RAPD in detecting polymorphism among different 26 cultivars of rice. The success of RAPD analysis in O. sativa accessions were also reported earlier (Muhammad et al., 2005; Rahman et al.,
2007; Malik et al., 2008). The percentage of polymorphism was found near to be $95 \%$. One of the reasons for this high level of polymorphism can be due to intraspecific variation among the cultivars. Information on intraspecific variation from the present 
study might be useful in making decision for improvement of rice cultivars. Similarity level up to $80 \%$ in cluster analysis is indicative of plant derived from interspecific hybridization (Marsolais et al., 1993). Six cultivars Aamchur, DPT-52, Gonor-1, Gundra, Guntur-2, Jeera Shankar, collected from Rice field Tumkur were grouped in a single cluster indicating more similarity among them and expressed more diversity from all the cultivars collected from traditional farmers of Tumkur. It is interesting to note that Giza 178, collected from farmers field of Tumkur was totally excluded from both the clusters. The findings of Reby Skaria et al. (2011) indicate that Gonor-1, Gundra, Guntur-2, are genetically distant.

The present findings confirm that genetic diversity of the plants is closely related to their geographic distribution. It has been reported that species with a wide geographic area generally have more genetic diversity (Wilikie et al., 1993). The present investigation reveals that RAPD is a valuable tool for estimating the extent of genetic diversity as well as to ascertain the genetic relationship between different cultivars of Oryza sativa.

In conclusion, the present study revealed that the levels of genetic differentiation between cultivars of $O$. sativa increased with geographical distance. The polymorphism detected among 26 accessions will be helpful in selecting genetically diverse cultivars in future breeding programme. However, there were some precincts in the present study that only twenty six cultivars and twenty primers were used in RAPD analysis and hence reduce the chance to obtain a reliable knowledge precisely about the genetic structure of each cultivar of rice. Further studies involving large number of accessions and primers need to be conducted to get more precise information.

\section{References}

Brar, D. S. and Khush, G. S. 2003. Utilization of wild species of genus Oryza in rice improvement, p. 283- 309. In: Nanda, JS, Sharma SD (Eds.). Monograph on Genus Oryza.

Byerlee, D. 1996. Knowledge-Intensive Crop Management Technologies: Concepts, Impacts, and Prospects in Asian Agriculture. International Rice Research Conference, Bangkok, Thailand, 3rd -5th June, 1996.

Chakravarthi, B. K. and Naravaneni, R. 2006. SSR marker based DNA fingerprinting and diversity study in rice (Oryza sativa L.). African Journal of Biotechnology 5(9): 684-688.

Chang, T. T. 2003. Origin, domestication and diversification. In: Smith, C.W. (Ed.), Rice: Origin, history, technology and production. John Wiley \& Sons, Inc.

Doyle, J. J. and Doyle, J. L. 1987. A rapid DNA isolation procedure for small quantities of fresh leaf tissue. Phytochemical Bulletin 19: 11-15.

Fischer, K. S., Barton, J., Khush, G. S., Leung, H. and Cantrell, R. 2000. Collaborations in rice. Science 290: 279-280.

Jaccard, P. 1908. Nouvelles recherches sur la distribution florale. Bulletin de la Societe Vaudoise des Sciences Naturelles 44: 223-270

Khush, G. S. 1997. Origin, dispersal, cultivation and variation of rice. Plant Molecular Biology 35: 25-34

Malik, A. R., Zahida, H. P. and Muhammad, S. M. 2008. Genetic diversity analysis of traditional and improved cultivars of Pakistani rice (Oryza sativa L.) using RAPD markers. Electronic Journal of Biotechnology 11(3): 1-10.

Marsolais, J. V., Pringle, J. S. and White, B. N. 1993. Assessment of random amplified polymorphic DNA (RAPD) as genetic marker for determining the origin of interspecific lilac hybrids. Taxon 42: 531537. Muhammad, A., Samina, K., Muhammad, A. B., Anjuman, A. and 
Yusuf, Z. 2005. Genetic diversity among rice genotypes of Pakistan through Random Amplified Polymorphic DNA (RAPD) analysis. Pakistan Journal of Botany 37(3): 585-592.

Ni, J., Colowit, P. M. and Mackill, D. J. 2002. Evaluation of genetic diversity in rice subspecies using microsatellite markers. Crop Science 42: 601-607.

Paranthaman, R., Alagusundaram, K. and Indhumathi, J. 2009. Production of Protease from Rice Mill Wastes by Aspergillus niger in Solid State Fermentation. World Journal of Agricultural Sciences 5: 308-312.

Ragunathanchari, P., Khanna, V. K., Singh, U. S. and Singh, N. K. 1999. RAPD analysis of genetic variability in Indian scented rice germplasm Oryza sativa L. Current Sciences 79: 994-998.

Ragunathanchari, P., Khanna, V. K., Singh, N. K. and Singh, U. S. 2000. A comparison of agarose RAPD and polyacrylamide RAPD to study genetic variability in Oryza sativa L. Acta Botany Indica 27: 41-44.

Rahman, S. N., Islam, M. S., Alam, M. S. and Nasiruddin, K. M. 2007. Genetic polymorphism in rice (Oryza sativa L.) through RAPD analysis. Indian Journal of Biotechnology 6(2): 224-229

. Ravi, M., Geethanjali, S., Sameeyafarheen, F. and Maheswaran, M. 2003. Molecular marker based genetic diversity analysis in rice (Oryza sativa L.) using RAPD and SSR markers. Euphytica 133: 243- 252.

Reby, S., Sen, S. and Muneer, P. M. A. 2011. Analysis of Genetic Variability in Rice Varieties (Oryza sativa L) of Kerala using RAPD Markers. Genetic Engineering and Biotechnology Journal GEBJ-24.

Rohlf, F. J. 1998. NTSYS-pc Numerical taxonomy and multivariate analysis system. Version 2.0. Exeter Publ, Setauket, New York.

Salim, M., Akram, M., Akhtar, M. E. and Ashraf, M. 2003. Rice, A production Hand Book. Pakistan Agricultural Research Council, Islamabad, p. 70.

Shivapriya, M. and Hittalmani, S. 2006. Detection of genotype specific fingerprints and molecular diversity of selected Indian locals and landraces of rice (Oryza sativa L.) using DNA markers. Indian Journal of Genetic and Plant Breeding 66: 1-5.

Sneath, P. H. A. and Sokal, R. R. 1973. Numerical taxonomy. Freeman, San Francisco, California, p. 573.

Thiyagarajan, T. M. and Selvaraju, R. 2001. Water saving in rice cultivation in India. In: Proceedings of an international workshop on water saving rice production systems. Nanjing University, China p. 1545.

Wilikie, S. E., Issac, P. G. and Slater, R. J. 1993. Random amplified polymorphic DNA (RAPD) markers for genetic analysis in Allium. Theoretical and Applied Genetics 87: 668-672.

Williams, J. G. K., Kubelik, A. R., Livak, K. J., Rafalski, J. A. and Tingey, S. V. 1990. DNA polymorphisms amplified by arbitrary primers are useful as genetic markers. Nucleic Acids Research 18: 6531-6535.

Xu, R., Norihiko, T., Vaughan, A. D. and Doi, K. 2000. The Vigna angularis complex: Genetic variation and relationships revealed by RAPD analysis and their implications for In-situ conservation and domestication. Genetic Resources and Crop Evolution 47: 123-134.

\section{How to cite this article:}

Roopa, B.R., and Chikkaswamy, B.K. 2016. Genetic Diversity and Relationship of Selected Cultivars of Rice, Oryza sativa L. using Random Amplified Polymorphic DNA (RAPD) Markers. Int.J.Curr.Microbiol.App.Sci. 5(9): 837-842. doi: http://dx.doi.org/10.20546/ijcmas.2016.509.094 